\title{
Involucrant a l'alumnat de primària en una pràctica científica autèntica: El taller Plantes Mutants
}

\author{
Èlia Tena Gallego (elia.tena@uab.cat) Centre de Recerca per a l'Educació Científica i Matemàtica \\ (CRECIM) - Universitat Autònoma de Barcelona (UAB) \\ Anna Garrido Espeja (agarridoespeja@gmail.com ) Centre de Recerca per a l'Educació Científica i \\ Matemàtica (CRECIM) - Universitat Autònoma de Barcelona (UAB) \\ Zoila Babot (zoila.babot@cragenomica.es).Centre de Recerca en Agrigenòmica (CRAG) CSIC-IRTA-UAB- \\ $U B$
}

En els últims anys ha anat creixen el nombre d'iniciatives que estableixen col/laboracions entre alumnat $i$ científics professionals. El present article, ofereix un exemple de taller d'aquest tipus que involucra a alumnat de 5è i 6è de primària en Pràctiques Científiques anàlogues a les dels científics del CRAG. Aquest taller permet als alumnes consolidar coneixements sobre les plantes i construir una primera idea de mutació. A més a més, la participació en aquest taller permet a l'alumnat desenvolupar una visió més positiva $i$ propera de la ciència real així com despertar el seu interès per la recerca científica y la feina dels investigadors.

Paraules clau: Educació Primària, Tallers Científics, Model ésser viu, plantes

In the last years, the number of collaborative work initiatives between children and professional researchers has been increasing. This article offers an example of a workshop that involves 9 to 12-year-old children in "real" scientific practices similar to what professional researchers do at CRAG. This workshop aims to help the students to consolidate their knowledge on plant biology and to build a first idea of genetic mutations. Furthermore, the workshop has a positive impact on the student's perceptions about science, helping them in developing a more accurate view of scientific research and in growing their interest towards it

Keywords: Primary School, Scientific Workshop, Living things model, plants

\section{INTRODUCCIÓ}

Existeix un consens generalitzat respecte a la necessitat d'alfabetitzar científicament a l'alumnat des de les etapes d'infantil i primària per tal de garantir que aquest pugui tenir accés a una ciutadania plena, esdevenint adults capaços de participar de la presa de decisions informada en els debats socials i problemàtiques científiques del segle XXI (OCDE, 2013).

No obstant això, actualment l'alfabetització científica al nostre país no és un aspecte trivial, tal com mostren els resultats dels estàndards internacionals (PISA, 2015), per la qual cosa ha esdevingut imprescindible buscar noves propostes didàctiques que promoguin l'alfabetització científica de tot l'alumnat $i$, molt especialment, d'aquells perfils que sovint estan infra-representats en l'àmbit: dones, minories ètniques i classes socials desafavorides.

La proposta de taller aquí presentada hi col-labora en aquest sentit, apropant la ciència a l'alumnat de primària $i$ promovent la seva participació en una pràctica científica autèntica. 


\section{FER, PARLAR I PENSAR EN CIÈNCIES A PRIMARIA}

Amb l'objectiu de millorar l'alfabetització científica de l'alumnat, ha aparegut una nova aproximació didàctica centrada en el foment de les Pràctiques Científiques (NRC, 2012), la qual es troba amb consonància amb propostes innovadores en el nostre context com és l'Activitat Científica Escolar (ACE) (Izquierdo, Espinet, García, Pujol i Sanmartí, 1999).

Aquests marcs manifesten la necessitat de fer participar a l'alumnat des d'infantil en pràctiques cognitives, discursives i socials genuïnes i racionals, anàlogues (tot $\mathrm{i}$ que no iguals) a les que desenvolupen els científics professionals (Izquierdo, 2005), on els alumnes hagin de fer, pensar i parlar tant de ciències (contingut científic) com sobre ciències (epistemologia de les ciències).

D'altra banda, involucrar als alumnes en aquestes pràctiques de ciència escolar hauria de tenir la finalitat de construir unes poques però importants idees científiques amb el potencial d'explicar una gran quantitat de fenòmens del món que ens envolta (Izquierdo, 2014; NRC, 2012). En aquest sentit, la pràctica científica de modelització permet que els alumnes vagin expressant, avaluant i modificant les seves idees sobre el món de manera progressiva, permetent que ells mateixos vagin construint un model cada cop més proper al científic (Acher, Arcà i Sanmartí, 2007).

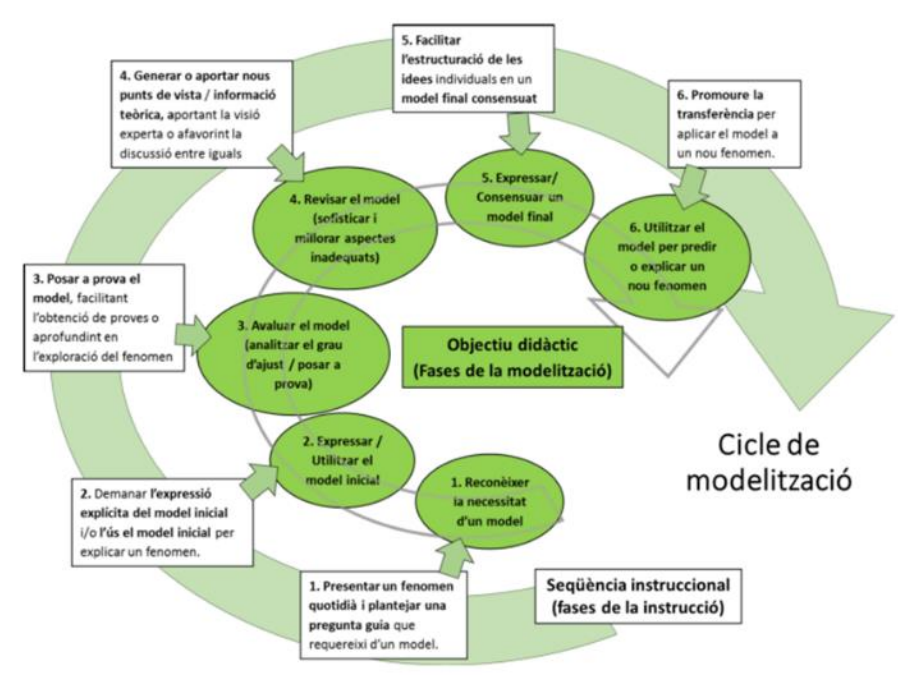

Figura 1. Cicle de modelització proposat per Garrido Espeja (2016)
En aquest sentit, el cicle de modelització de Garrido Espeja (2016) és un recurs útil per dissenyar i seqüenciar activitats que involucrin a l'alumnat en el procés de modelització (Figura 1).

\section{CONTEXTOS D'APRENENTATGE AUTÈNTIC}

Un bon context per a que l'alumnat s'involucri en construir i fer ciències d'una manera autèntica és promovent la relació entre professionals científics en actiu i alumnat.

En els últims anys ha augmentat el nombre de propostes de col-laboració d'aquest tipus, liderades per centres de recerca, universitats i empreses de l'àmbit científic. Aquestes institucions organitzen tallers experimentals de curta durada per a estudiants de primària i secundària a les seves instal-lacions perseguint principalment tres objectius (Hernández i Couso, 2016):

1) Contribuir a la millora de la cultura i la alfabetització científica de l'alumnat (p. ex. desenvolupant coneixement conceptual, procedimental, epistèmic i actitudinal);

2) Afavorir les vocacions STEM entre infants $i$ joves (p. ex. millorar la percepció d'autoeficàcia, trencar estereotips, millorar la imatge social de les carreres...)

3) Afavorir el diàleg entre el públic i els investigadors ( $p$. ex. generar la necessitat de desenvolupar coneixement mitjançant preguntes, connectar idees prèvies amb vocabulari específic...).

\section{PER QUÈ PARTICIPAR AMB ALUMNES DE PRIMÀRIA EN AQUESTS TALLERS?}

El foment de les vocacions científiques pot semblar important únicament per a les etapes de ESO i Batxillerat però algunes recerques (Archer i altres, 2013) han posat de manifest la importància de l'etapa final de primària i la inicial de secundària en el posicionament de l'alumnat respecte a les ciències. A més a més, s'ha observat que aquest posicionament condiciona l'elecció més endavant dels estudis post-obligatoris.

És per tot això que considerem imprescindible que les col-laboracions entre científics i alumnat es fomentin ja durant l'etapa de primària i una bona manera de fer-ho és fent participar als alumnes 
d'aquestes edats en tallers científics organitzats pels propis centres de recerca.

\section{“PLANTES MUTANTS": UNA PROPOSTA DE TALLR PER ALUMNAT DE PRIMÀRIA ORGANITZADA PER CIENTÍFICS}

El taller que es presenta continuació va dirigit a l'alumnat de 5 è $i$ Gè de primària, i es va desenvolupar, implementar i avaluar pel Centre de Recerca en Agrigenòmica (CRAG) i el CRECIM durant el curs 2017-18.

Aquesta proposta es dissenya en base al Cicle de Modelització de Garrido Espeja (2016) presentat anteriorment i busca involucrar a l'alumnat en fer, pensar i parlar d'algunes idees clau del model ésser viu (concretament dels organismes vegetals) millorant, d'aquesta manera, el seu posicionament cap a les ciències, en concret la recerca en plantes. Al taller es treballa una primera idea de mutació tot involucrant als alumnes de primària en un procés de recerca guiat que els obligarà a fer hipòtesis, argumentar en base de proves, trobar solucions de consens i utilitzar la seva creativitat. Alhora es busca trencar alguns dels estereotips més arrelats sobre els científics (p. ex. que només són homes, que sempre van amb bata...) i sobre la recerca en plantes ( $p$. ex. que és avorida, que no serveix, que és perillosa o poc ètica...).

Aquest taller té una durada de 2 hores i, tot i que s'ofereix realitzar-lo en el propi Centre de Recerca, s'ha realitzat exitosament també en diversos centres educatius amb el material proporcionat pel CRAG (plàntules d'Arabidopsis thaliana cultivades en placa de petri). A continuació s'explica i es justifica el taller, donant comptes dels beneficis que aporta a l'alumnat. El protocol complert i els materials de suport es poden descarregar en anglès (Babot, Martí, Garrido, Tena, 2017).

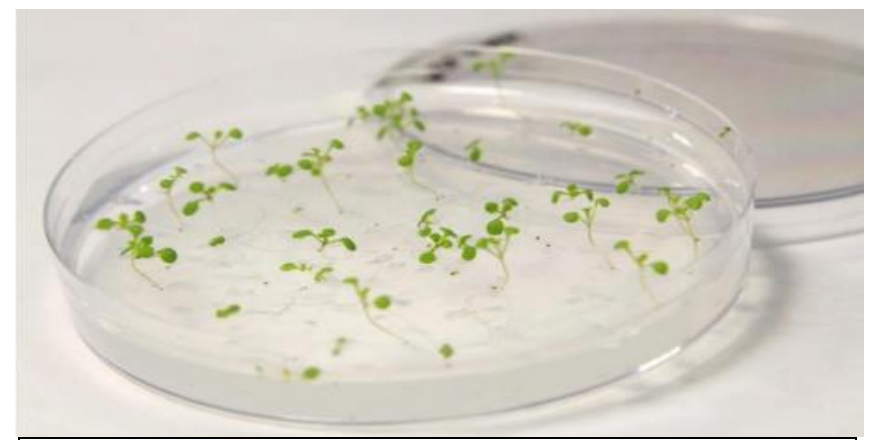

Figura 2. Plàntules d'Arabidopsis thaliana cultivades en placa de petri

\section{Observem les plantes! Un primer contacte (15')}

Dividirem a l'alumnat en grups i els demanarem que identifiquin i argumentin quina és cada una de les 3 plantes que tenen sobre la taula: una tomaquera (amb una olor i fruit molt coneguts pels alumnes), una planta d'arròs (amb alguna llavor també coneguda pels infants) i una planta d'arabidopsis (totalment desconeguda pels alumnes). Per identificar les plantes, proposarem que observin, toquin, olorin... les fulles, el fruit i les llavors, i preguntarem si alguna part els hi recorda a alguna planta coneguda, etc. D'aquesta manera, els alumnes es començaran a involucrar en pràctiques habituals de la recerca professional amb plantes: observar amb deteniment, connectar amb el coneixement previ sobre el tema, argumentar...

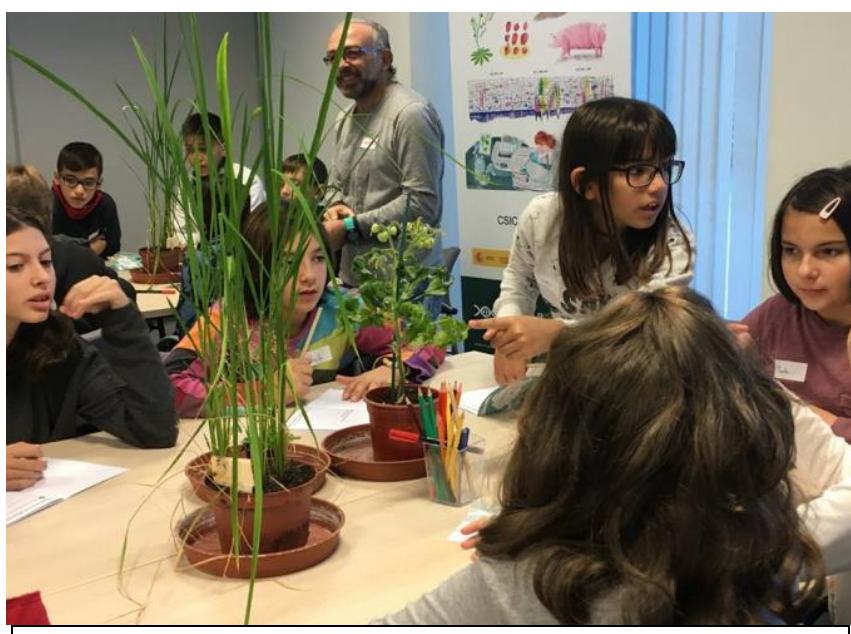

Figura 3. Alumnes observant les diferents parts de les plantes per identificar-les

A continuació, posarem en comú les observacions que els han permès identificar cadascuna de les plantes. Aprofitarem aquest moment per reflexionar sobre el motiu pel qual els científics fan servir aquestes plantes i no unes altres per investigar ( $p$. ex. que són plantes de mida manipulable i que creixen ràpid, de les quals ja se saben algunes coses....).

\section{Els científics ens necessiten. Presentem el context (20')}

Seguidament ensenyarem a l'alumnat un vídeo de dos investigadors principals del CRAG: en Jaume Martínez i la Soraya Pelaz. En aquest, els investigadors es presentaran explicant què els agrada, quines qualitats ha de tenir un científic $i$ algunes característiques de la seva línia de recerca 
de manera molt senzilla. Intentant trencar així algunes idees estereotipades sobre la feina de científic (persona excepcional, solitària, gran, dedicada únicament a la ciència....).

Al final del vídeo els científics demanen ajuda als alumnes per identificar i diferenciar les plantes mutants de les silvestres, les quals se'ls han barrejat en unes plaques de petri.

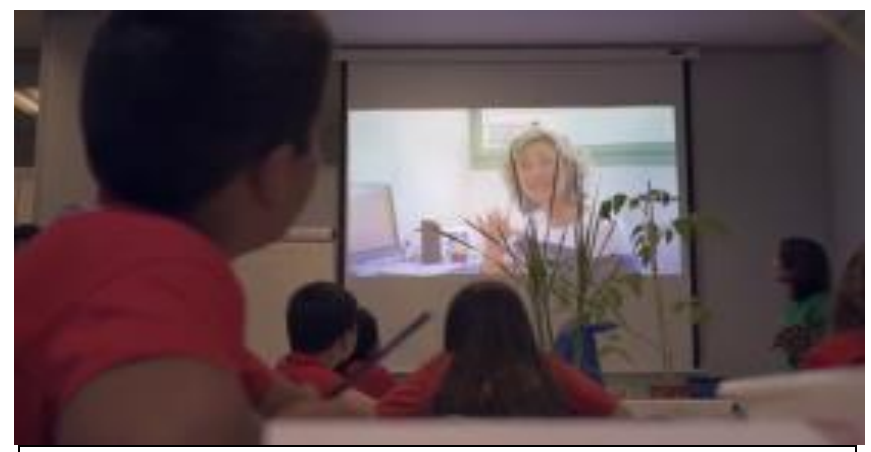

Figura 4. Alumnes veient el vídeo on els científics del CRAG els demanen ajuda.

Ajudar als científics a resoldre el problema obliga a l'alumnat a utilitzar diferents materials de laboratori amb els que no acostuma a treballar: lupes binoculars, plaques de petri amb agar-agar, mostres vives, etc. Es planteja doncs un treball de manera pautada i regulada per tal que els alumnes aprenguin a utilitzar el material adequadament...

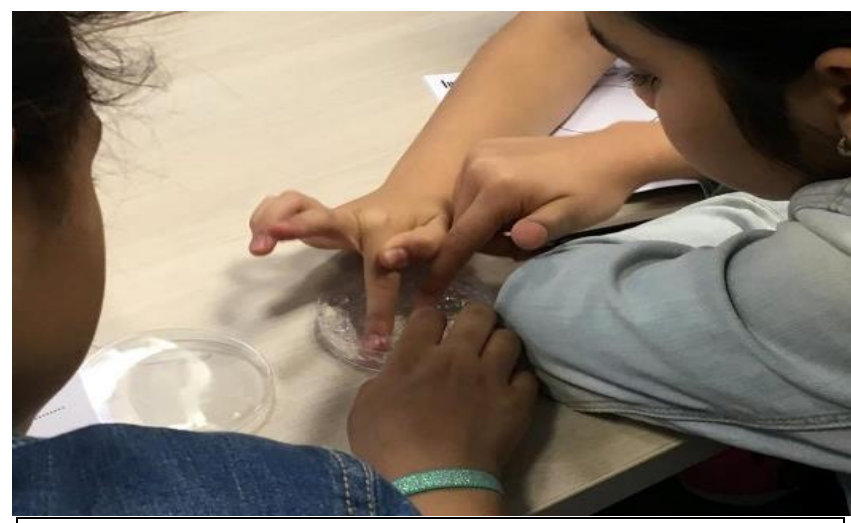

Figura 5. Alumnes tocant l'Agar-agar.

\section{Com ens imaginem els mutants? Expressem els nostres models inicials (5')}

A partir d'aquest moment la meitat dels grups treballarà amb la recerca de la Soraya: diferenciant plantes mutants sense pèls (tricomes) de plantes silvestres (amb pèls). L'altre meitat treballarà en la recerca d'en Jaume: diferenciant les plantes mutants que no perceben bé la llum d'aquelles silvestres que sí ho fan.

Abans de començar les observacions demanarem als alumnes que facin una predicció: hauran de pensar i argumentar com creuen que seran les plantes silvestres i les mutants. Posarem en comú les idees sorgides per a què els infants esdevinguin conscients que existeixen diferents explicacions possibles.

Fins al moment ni monitors ni alumnes van vestits amb bata de laboratori amb l'objectiu de trencar alguns estereotips científics: que vegin que són persones normals, que no sempre porten bata, etc. A partir d'ara, que comença la part més experimental i el treball amb mostres, tots utilitzarem bates. Tot i semblar anecdòtic, aquest fet pot ajudar a l'alumnat sentir-se més capaç de fer ciències i més propers als científics professionals.

\section{Investiguem com a científics! Posem a prova els nostres models (40')}

A continuació es reparteixen les plaques de petri. Els diferents grups observen les plantes a través de la lupa i identifiquen amb un retolador quines són mutants i quines no.

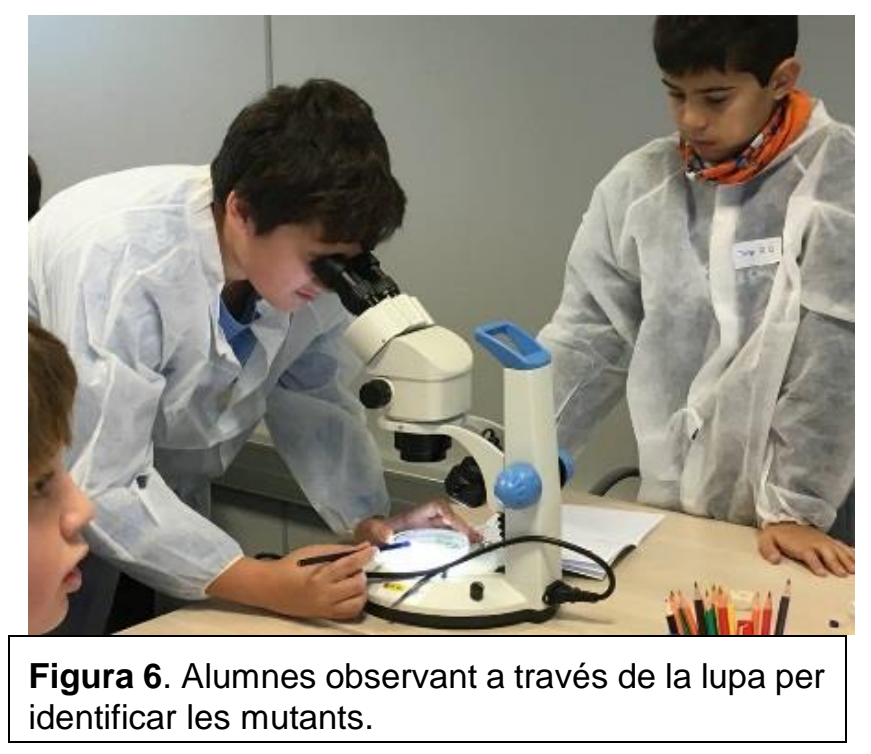

Seguidament, de manera individual, els alumnes dibuixen a la seva llibreta el han observat tot ressaltant les diferències entre plantes mutants $i$ salvatges (figura 7). 

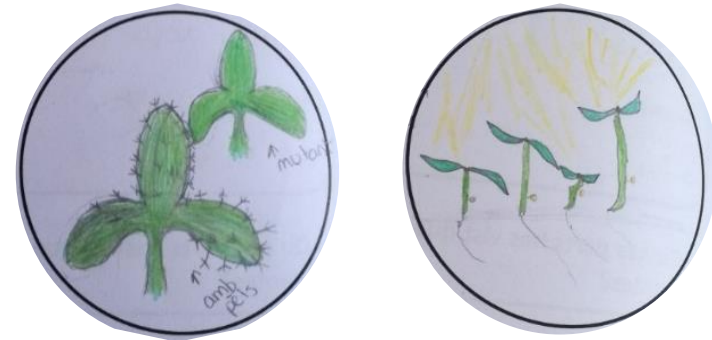

Figura 7. Dibuix d'un alumne d'una planta silvestre amb pèls i d'una planta mutant amb pocs pels (esquerra) i Dibuix d'una planta mutant que no veu bé la llum i per tant creix més, fet per un alumne

\section{Què ens explica el que hem observat? Revisem els resultats (10')}

Finalitzades les observacions fem una posada en comú on els diferents grups descriuen i comparteixen amb els seus companys les seves observacions. Seguidament, s'intercanvien les plaques de taula per tal que tots els grups puguin veure totes les mutants i així ratificar la informació donada pels seus companys.

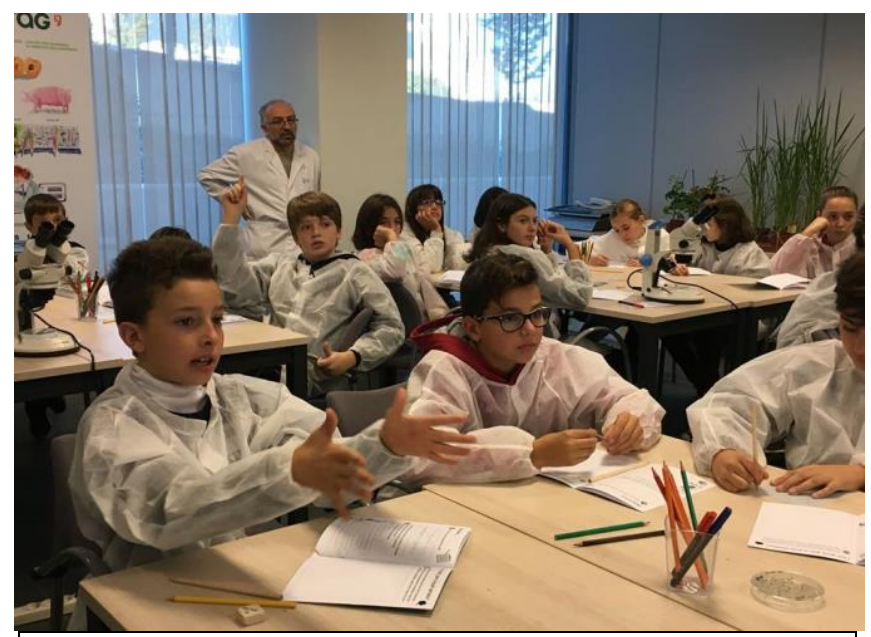

Figura 8. Posada en comú del taller: l'alumnat comparteix amb els seus companys què han observat amb la guia de la monitora.

\section{Què és una planta mutant? Consensuem un model (5')}

Amb l'objectiu que l'alumnat pugui arribar a construir una primera idea de mutació més general, i no només lligada a les mutacions observades, demanem que escullin entre 5 opcions quina creuen que és la descripció més correcta de planta mutant. A continuació, posem en comú les respostes i aprofundim en la idea que les plantes mutants són aquelles que tenen una informació diferent en el seu llibre d'instruccions (DNA) i això les fa diferents a les altres (amb diferent aspecte, capacitats, etc.).

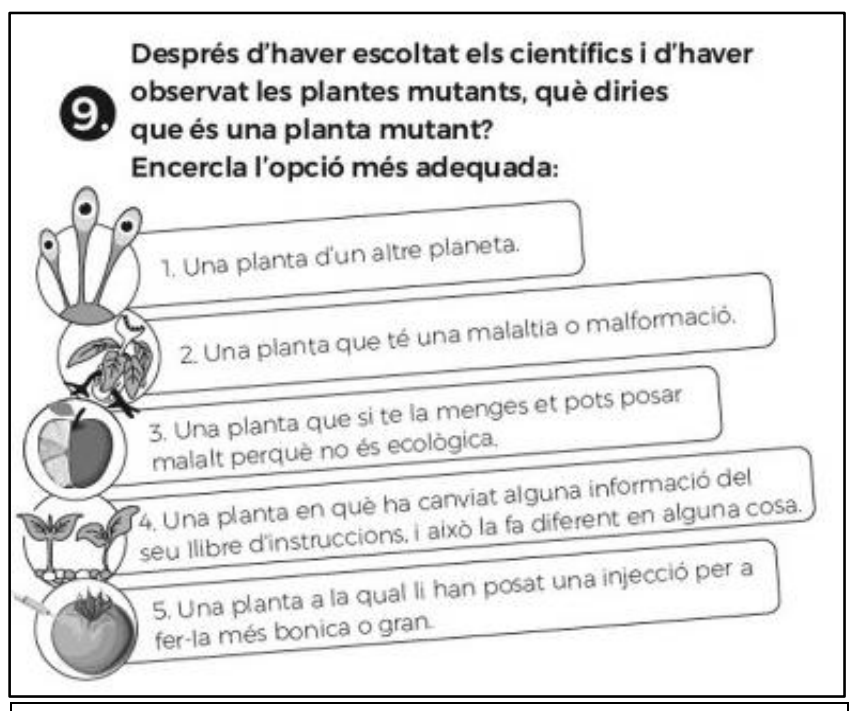

Figura 9. Pregunta per ajudar als alumnes a consensuar la idea de mutant.

\section{I tot això, per a què serveix? Pensem en aplicacions d’aquesta recerca (25')}

A continuació demanem a l'alumnat que pensi possibles aplicacions reals i/o útils de la recerca amb plantes, i en concret d'aconseguir mutacions com les que han vist: que les plantes tinguin més 0 menys pèls $i$ que vegin millor o pitjor la llum. A mesura que l'alumnat va proposant aplicacions, aquestes es van comentant i se's hi expliquen algunes aplicacions reals que s'estan donant actualment amb aquest tipus de recerques (p. ex. als pèls de les plantes podem trobar medicaments que ajudin a tractar malalties com el càncer, etc.).

\section{Anem a explicar les nostres troballes als investigadors!: Comuniquem els nostres resultats i visitem les instal-lacions (20')}

Per últim, els alumnes porten les plaques de petri amb les plantes identificades a la Soraya i en Jaume. Aquests estan al laboratori on treballen normalment de manera que els alumnes tenen la oportunitat de conèixer l'espai real on treballen els científics (laboratoris, hivernacles...). 


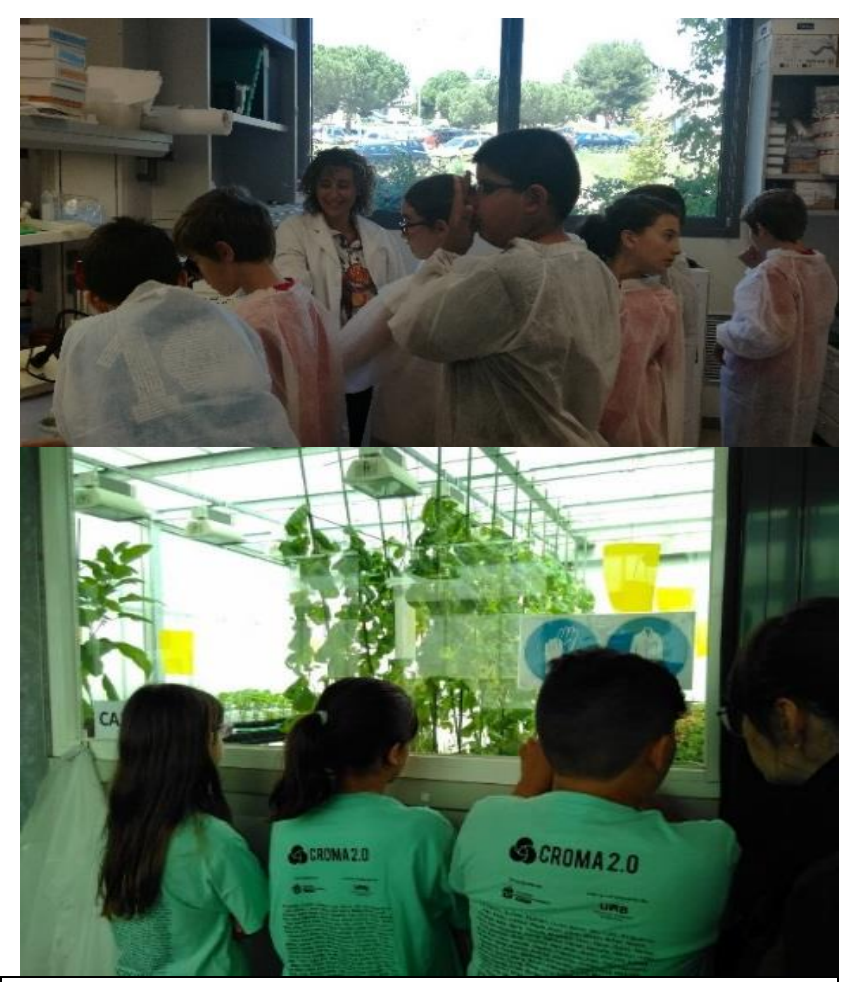

Figura 11. Alumnes mostrant i explicant a la investigadora Soraya Pelaz les seves troballes i visitant hivernacles del CRAG

\section{RESULTATS DEL TALLER I CONCLUSIONS}

El taller descrit, implementat diverses vegades durant el curs 2017-2018, es va analitzar i avaluar amb l'objectiu de conèixer fins a quin punt aquest era útil per a: i)promoure la pràctica científica de l'alumnat i l'aprenentatge de idees científiques, ii)donar una visió de la ciència i els científics més positiva i real, iii) promoure vocacions científiques i iv) apropar la investigació en plantes a l'alumnat. Per això, es van gravar les sessions i recollir les produccions escrites de l'alumnat, analitzant posteriorment les idees, actituds, coneixements i opinions dels i les alumnes participants.

Els resultats d'aquesta avaluació ens mostren que durant el taller l'alumnat de primària ha estat capaç de reconèixer les diferències més significatives entre les plantes silvestres i mutants observades a través de la lupa binocular, han pogut identificar l'expressió de les mutacions (plantes més o menys llargues i plantes més o menys peludes) i han reproduït exitosament aquestes diferències significatives en un dibuix i per escrit. A més a més, en acabar el taller tots els alumnes han estat capaços de destacar algunes utilitats de la investigació en plantes, vinculades a la creació de nous coneixements, a aconseguir nous productes útils per a la societat o ambdues utilitats a l'hora.

A banda d'això, és important destacar que durant tot el taller l'alumnat es va implicar de manera activa en les pràctiques científiques professionals, tals com fer hipòtesis, fer observacions acurades, usar material de laboratori, identificar proves, buscar explicacions i justificar-les... A més, involucrar a l'alumnat en aquest tipus de pràctiques de manera activa ha promogut desenvolupar una visió més positiva i propera de la ciència real. Alhora, també s'ha observat una millora del coneixement i l'interès dels nens i les nenes per l'activitat científica i per la feina dels investigadors, en especial per la recerca en plantes. Alguns d'ells fins i tot reconeixen el seu interès personal per dedicar-se en un futur investigar les plantes.

La imatge del científic amb la qual marxen els alumnes d'aquest taller és la d'una persona real, propera i no estereotipada (p. ex. jove, dona, agradable, apassionada, divertida...), així com amb una idea de l'activitat científica més positiva i realista que la habitual, atribuint aspectes com ser creatiu, saber treballar en equip o ser bon observador com habilitats necessàries per ser un bon científic. El vídeo promocional [2] reflecteix alguns d'aquests resultats.

\section{AGRAIIMENTS}

El desenvolupament d'aquest taller es va fer en el marc d'un projecte finançat per la FECYT (FCT16-10825), el programa Severo Ochoa de Centres d'Excel-lència en R\&D 2016-2019 (SEV-2015-0533) i el projecte "Participación reflexiva de profesorado y alumnado en las prácticas científicas: Potencialidades, desafíos y criterios didácticos" (EDU2015-66643-C2-1-P) tots ells del Ministeri d'Economia, Indústria i Competitivitat. Les autores volen agrair la participació en el disseny i execució del taller al Dr. Jaume Martínez-García, Dra. Soraya Pelaz, Dra. Irma Roig-Vilanova i Dra. Paula SuárezLópez, a la Margalida Martí i als alumnes participants en el taller de l'Escola Joan Maragall i del programa CROMA-FAS.

\section{BIBLIOGRAFIA}

ACHER, A., ARCÀ, M., SANMARTÍ, N. (2007). Modelling as a Teacher Learning Processo for Understanding Materials: A Case Study in 
Primary Education. Science Education, 91(1), 398-418.

ARCHER, L., OSBORNE, J., DEWITT, J., DILLON, J., WONG, B., WILLIS, B. (2013). ASPIRES.

Young people's science and career aspirations, age 10-14. London.

BABOT, Z., MARTÍ, M., GARRIDO ESPEJA, A., TENA, E. (2017). "Mutants plants" workshop protocol : didactic guide for researchers and instructors to conduct a science workshop with groups of school students aged 10 to 14. CRAG i CRECIM.

GARRIDO ESPEJA A. (2016). Modelització $i$ models en la formació inicial de mestres de primària des de la perspectiva de la pràctica científica. Universitat Autònoma de Barcelona.

HERNÁNDEZ, M. I., COUSO, D. (2016). Comunicando ciencia en talleres experimentales para estudiantes de educación primaria y secundaria: Aportaciones de la didáctica de las ciències experimentales al diseño, implementación y evaluación de talleres de comunicación científica. CRECIM.
IZQUIERDO, M. (2005). Hacia una Teoría de los Contenidos Escolares. Enseñanza de Las Ciencias, 23(1), 111-122.

IZQUIERDO, M. (2014). Los modelos teóricos en la enseñanza de las "ciencias para todos" (ESO, nivel secundario). Biografia, 7(13), 69-85.

IZQUIERDO, M., ESPINET, M., GARCÍA, M. P., PUJOL, R. M., SANMARTÍ, N. (1999).

Caracterización y fundamentación de la ciencia escolar. Enseñanza de Las Ciencias, número extra, 79-91.

NATIONAL RESEACH COUNCIL. (2012). A Framework for K-12 Science Education: Practices, Crosscutting Concepts, and Core Ideas. A framework for K-12 Science Education: Practices, Crosscutting Concepts and Core Ideas. Washington DC.

OECD. (2013). Pisa 2015 draft science framework.

[1] Video de taller Plantas Mutantes:

https://www.youtube.com/watch?v=WcH7EqQV2d8 